\title{
University praxis. On exchange between professional and academic practices in architectural education
}

\author{
Mark Southcombe, Andrew Charleson \\ Victoria University of Wellington, New Zealand \\ School of Architecture \\ Mark.Southcombe@vuw.ac.nz | Andrew.Charleson@vuw.ac.nz
}

\begin{abstract}
This paper records and reflects on two architecture design studios situated between academic and professional practice contexts. It is motivated by the level of both student and external engagement generated by the studios, which occurred at a significantly higher level than that generated by similar studios that regularly run at VUW School of Architecture and other schools of architecture. The objective is to retrospectively understand the unique or special aspects of these studios for future reference.

As a working method, the Cuba Street studios are first described in terms of the motivation, the context, the community engagement set up, their brief and their modus operandi. Outcomes of the studios are then evaluated through our observations and critical reflection on the ways engagement between University and professional practices occurred, and how these interactions affected the student learning and external engagement. Reference is made to the relevant literature, the critical intents of the studios, the immediacy of both the proximity and the seriousness of the motivating problem, the inputs of external bodies, and the detail of the student outcomes in terms of both expectations, and the nature of the outcomes.

The paper argues that clarity about characteristics, strengths and weaknesses of academic practices, can augment the potential effectiveness of future architecture design teaching associated with professional engagement, and that the collective framing of student research-led design can deliver research outcomes with a significance greater than the sum of their parts.
\end{abstract}

Keywords: architectural education, praxis, heritage, seismic retrofit, urban regeneration.

To cite this article:

Southcombe, M., Charleson, A. (2017). University praxis. On exchange between professional and academic practices in architectural education. The Journal of Public Space, 2(3), Special Issue, I57166, DOI: 10.5204/jps.v2i3.124

This article has been peer-reviewed and accepted for publication in The Journal of Public Space. Please see the Editorial Policies under the 'About' section of the journal website for further information.

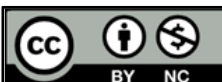

This work is licensed under a Creative Commons Attribution - Non Commercial 4.0 International License https://creativecommons.org/licenses/by-nc/4.0/ 


\section{Introduction}

The Cuba Street studios were motivated by architectural opportunities following the post Christchurch earthquakes. There was an urgent need to educate students, building owners, and the local public around the need to seismically-upgrade dangerous' historic building stock as found in the Cuba Street precinct of Wellington, and about the architectural design implications associated with this context.

The studios operated as a research partnership with Wellington City Council and Heritage New Zealand. They addressed design opportunities arising from building reuse and the renewal of urban form, the need for structural upgrading, heritage retention and adaptation, and the intensification and integration of new buildings into a listed precinct. The design studios integrated teaching collaborations across parallel technology courses to create student opportunities for applied and collaborative learning.

The studios delivered high levels of student, community, and disciplinary engagement ${ }^{2}$. This paper is motivated by curiosity about why and how the studios had delivered these outcomes? We wanted to establish if the studios had ongoing pedagogic relevance, and what the impact of the engagement with local community and professional practice contexts upon student learning had been. The studios included collaboration between the Wellington City Council, Heritage New Zealand, and Victoria University of Wellington School of Architecture, and were held in the second Trimesters of 2012 and 2013 . There were inputs from a large group of Wellington professional Architects and Structural Engineers as specialist tutors and critics.

Architectural education both prepares students to practice architecture and advances wider disciplinary knowledge through research and teaching ${ }^{3}$. These two aspects of architectural education are both complementary and in tension ${ }^{4}$. Professional engagement typically occurs through the introduction of professional architects as tutors and guest lecturers, and working on 'real world' projects and briefs that simulate practice conditions creating unconscious bias towards the value of practice-based knowledge. The Cuba Street Studios were based on the proposition that this engagement may also be a means for the critical generation of disciplinary knowledge through engagement with practice-based modus operandi. This paper teases out results from the professional and academic design-led research practices to illustrate particular characteristics and tendencies of the studios in order to augment the potentials of professionally engaged future design teaching.

\footnotetext{
I 185 people from 17 nationalities died in the Christchurch earthquakes. In almost every case they were killed directly or indirectly by the buildings that collapsed on them. See Once in a lifetime; City building after Disaster in Christchurch, edited by Bennett Barnaby, Dann James, Johnson Emma, Reynolds Ryan, Freerange Press, Christchurch, 2014: 18.

${ }^{2}$ Public meetings, lectures, and exhibitions occurred on the 26 July and $19^{\text {th }}$ Nov 2012 , 17 July and $7^{\text {th }}$ Nov 2013 VUW Te Aro Campus, Wellington Town hall 26-28 ${ }^{\text {th }}$ April 20I3, $8^{\text {th }}$ April 2014 and $21^{\text {st }}$ March 2014 Whanganui, Heritage NZ Central Region New Plymouth 5 Oct 2014, Conference presentations to NZIA conference 2I March 2014, AASA - Association of Architecture Schools of Australasia, 2-3 October 2015. ${ }^{3}$ Architecture teaching programmes are subject to regular professional review to ensure that their content and delivery are acceptable as a basis for graduate students to enter the architecture profession. In New Zealand this occurs through the Registered Architects Board and its professional programme reviews in reference to the Australian Institute of Architects National Competency standards in Architecture as a basis for registration as an architect under the New Zealand Registered Architects Act 2005.

${ }^{4}$ Peter Rowe, "Shaping Design Education", in William Saunders, Reflections on Architectural practices in the 1990's, Princeton Architectural Press, 1996, 242 (is typical of the well traversed discourse in this area).
} 


\section{Description of the Studios}

In $201 \mathrm{I}$ after the Christchurch earthquakes, the potential in Wellington for similar catastrophic damage to buildings and loss of lives was apparent. This prompted two student projects focused on Cuba Street, part of the immediate environment of the Victoria University of Wellington (VUW) School of Architecture.

The studios were framed as an opportunity to critically revisit perennial architectural problems associated with working within and alongside existing building form, structure, space and fabric. Essential to the project were inherent issues of assessing design quality in whole and in part as a means to discuss architectural heritage, and in particular, the architectural qualities and values of heritage and how these may be worked with and against. A theoretical context was provided through a range of readings including the key text Moments of Resistance that includes the essay Binding Issues and Critical Strengthening by Michael Ostwald ${ }^{5}$.
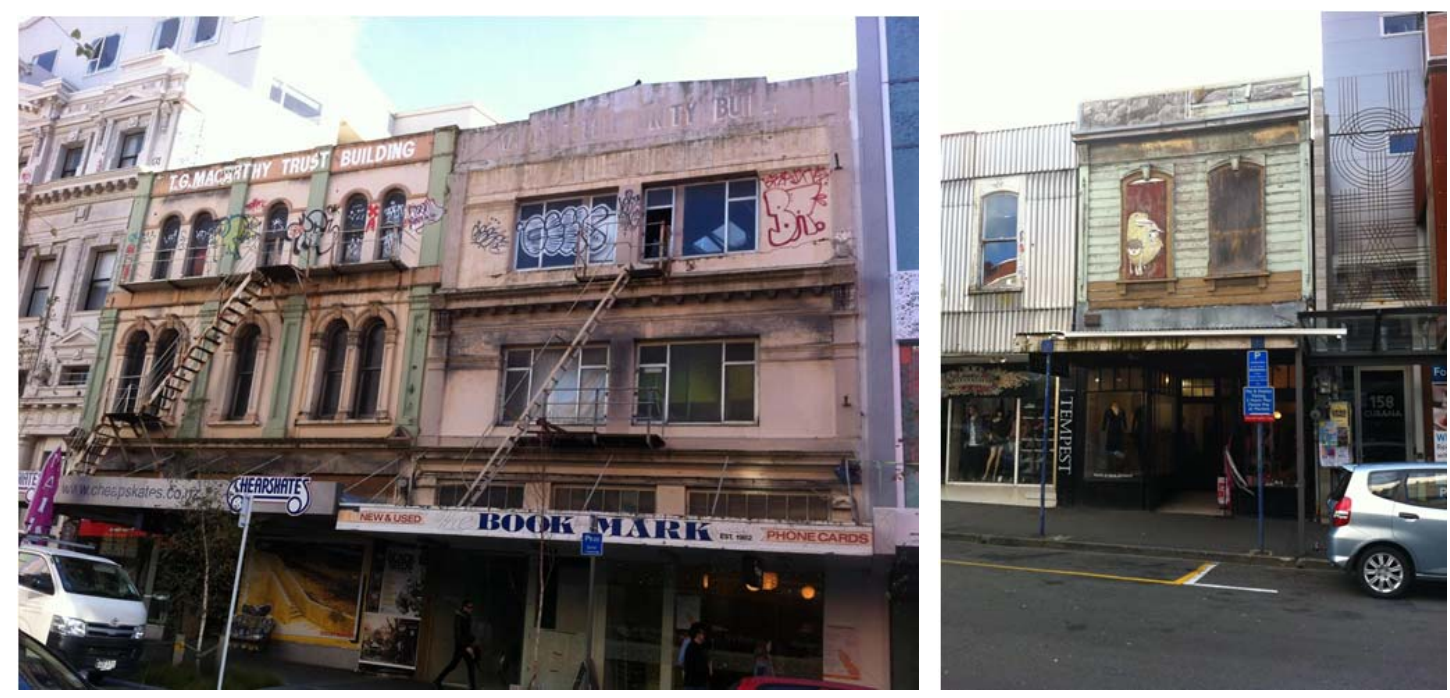

Figure I (left). Lower Cuba Street buildings.

Figure 2 (right). Upper Cuba Street Buildings June 2012.

The precinct is designated as the Cuba Street Character Area in the City Plan and has a collective formal heritage status with Heritage New Zealand. There was also widespread ignorance and apathy in the student and wider community about the nature, extent and urgency of the local seismic resilience problem, the need to structurally upgrade most of the existing buildings, and the extent of the architectural opportunities inherent in the problem. A crude understanding of the problem as a non-architectural, purely engineering and economic matter was accentuated by a level of antipathy towards local government-enforced strengthening, and a perception by building owners and engineers that there was a lack of architectural need and opportunity associated with the heritage designation.

VUW School of Architecture, along with Wellington City Council (WCC), Heritage New Zealand (HNZ), and a group of owners, recognised the potential of focusing VUW student architectural research on this urgent architectural problem. WCC wanted to raise awareness of the need to seismically upgrade most of the buildings in Cuba Street, and the range of ways this might occur. VUW created an opportunity to simulate a real world

\footnotetext{
${ }^{5}$ Michael J. Ostwald, Binding Issues and Critical Strengthening in Mark Taylor, Julianna Preston and Andrew Charleson. Moments of Resistance. 2002. Archadia Press, Sydney, 23-50.
} 
research-led design studio to address disciplinary knowledge at the same time as meeting the architecture programme accreditation need for an integration of design and technical competencies. Heritage New Zealand was concerned about the potential loss of a significant amount of heritage building fabric, and the public perception that there were few options available for building owners faced with the significant cost of upgrading their buildings. The student projects briefs were ambitious, considering implications of the seismic issue at a building and city precinct scale for all of the buildings on both sides of the ten-block length of Cuba Street. The larger intention was to simulate the effects of major development on the entire precinct of the city as a means to create a collective vision of a part of the future city, and to expand the discourse around the potential range of architectural approaches to the heritage and seismic retrofit issue.

The students designed a redevelopment for every building and site. They also considered wider and innovative design questions associated with clusters of related new and old buildings, potential intensification, and new work triggered by the need for seismic upgrades. An architectural practice working method was adopted where students worked in project groups. They collectively drew existing buildings to document the entire site with the consistency and clarity expected in professional practice as a means to deeply engage with both the extant built fabric they inherited, and its comparative value. Extensive urban mapping ${ }^{6}$ and existing condition documentation was created in groups that required cooperation to produce a series of related compatible outcomes, and share the workload. Digital and I:I00 physical models of the entire street and its existing individual buildings were made as a starting point.

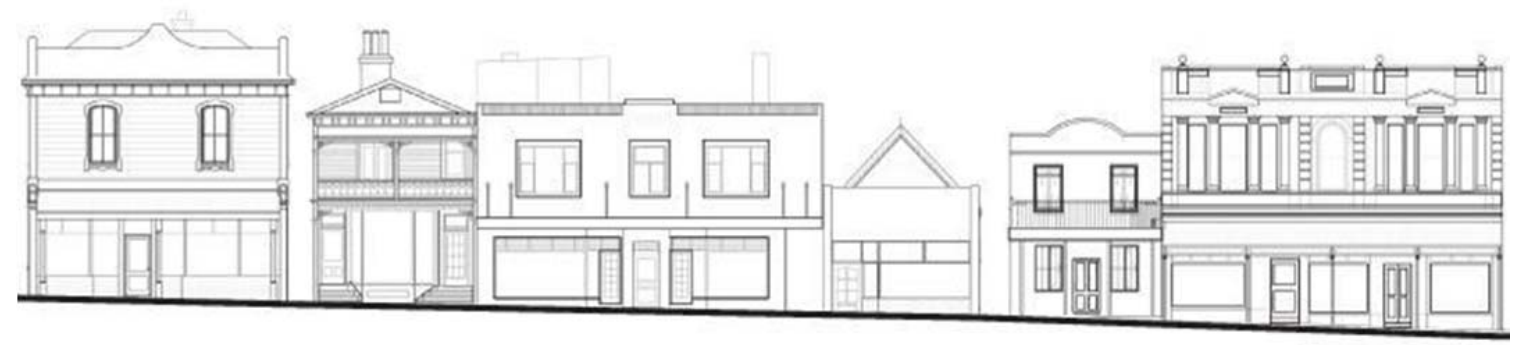

Figure 3. Collective Street Elevation Upper Cuba Street.

The students' documentation of the existing conditions of each building drew from free access to WCC's extensive plan archives. Students also made diagram-based critiques and adaptations of the WCC planning rules as they applied to the sites, and undertook Heritage Assessments and Condition Reports with expanded analysis for each existing heritage building and its fabric. This detailed student research then provided a basis to manipulate, modify and remove heritage fabric in whole or in parts. Student Thomas Strange noted I decided to replace this building. My research showed few historically or aesthetically redeeming features. And don't you think the original Victorian roof lantern on the building next door is much more intriguing? $?^{7}$ These methodologies were far from procedural, neutral, or technocratic. They created significant architectural learning opportunities through drawing out deep

\footnotetext{
${ }^{6} 36$ separate categories of urban mapping were investigated by each student group in a manner that coordinated student graphic conventions and that covered the entire urban precinct.

${ }^{7}$ Thomas Strange, quoted by Jacqui Gibson, Future Perfect, Heritage New Zealand, Autumn 2013, 29
}

160 | The Journal of Public Space, 2(3), 2017 | Special Issue | ISSN 2206-9658

(C) Queensland University of Technology 
student critical judgement of existing architectural contexts. There was also significant added value to every student from the exchanges of foundational information and working techniques with each other. Students quickly learnt the value of focused team work in terms of both the peer-to-peer learning and the scale of the local, group, and combined outcomes.
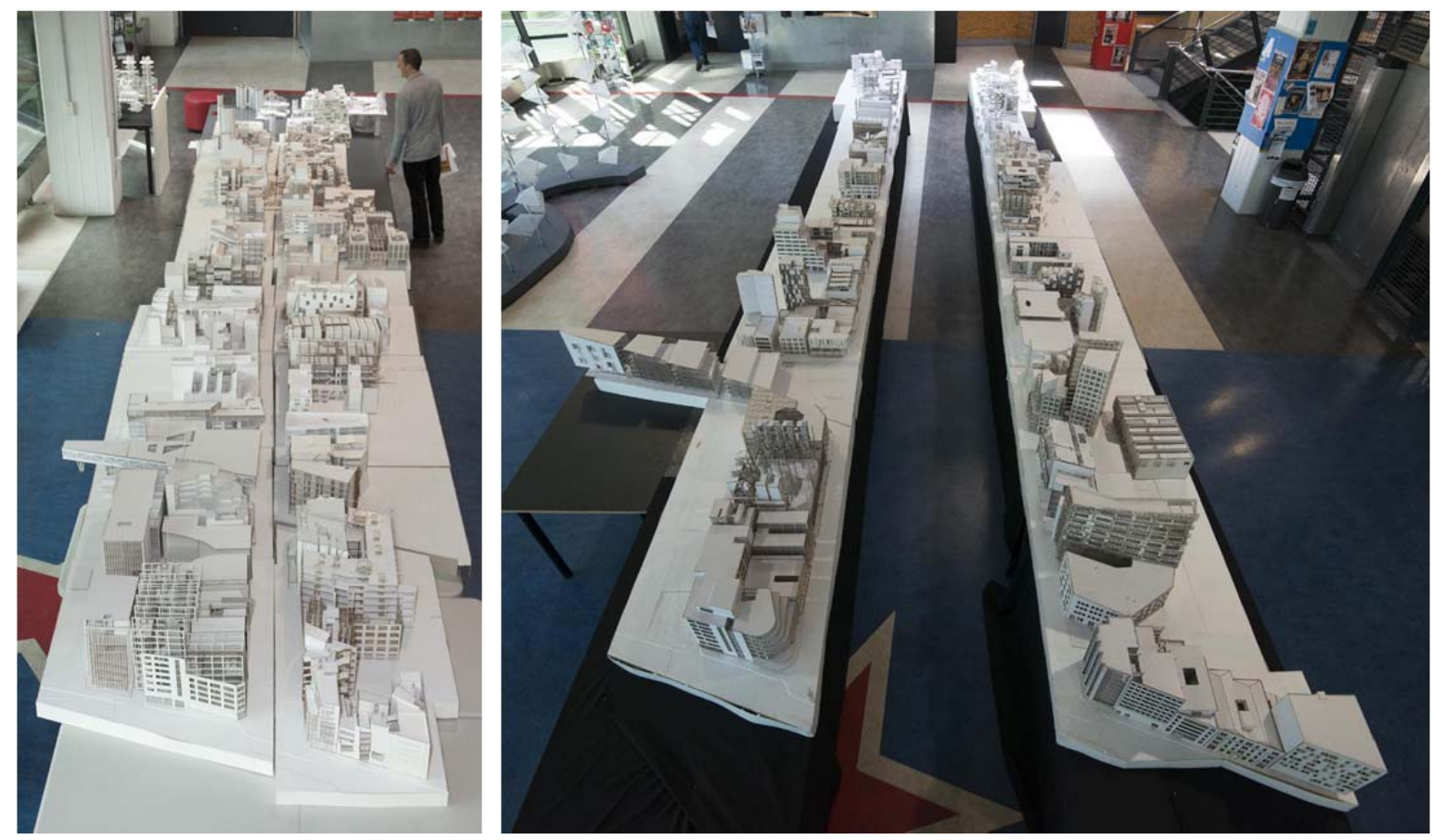

Figure 4 (left). Cuba Street Model Nov 2012.

Figure 5 (right). [Re]Cuba Model Nov 2013.

Stakeholder meetings with students and owners in Cuba Street were facilitated by WCC. Formal presentations about the project were made to Cuba Street building owners and the public by VUW, WCC and HNZ staff. The design studios also integrated teaching collaborations across parallel technology courses. As part of their architectural designs the students designed and integrated seismic retrofitting schemes to meet the requirements of the Building Act and the parallel Integrated Technologies courses. Structural, construction, and services knowledge was integral to seismic and architectural retrofit schemes for individual buildings and the clusters of buildings, including the intensification and the new work. The structural assessments and proposed seismic upgrade designs findings were made available to owners through the VUW architecture library. It is rare for clusters of buildings to be tied and seismically retrofitted together, so this phase of the project developed important new research around the potentials of buildings to structurally support each other. This was a contribution to the field that has been subsequently recognised in several forums, and published in a separate national engineering publication ${ }^{8}$.

\section{Outcomes of the studios}

A rich range of context-specific design outcomes emerged. These interwove retrofitted structure with existing and proposed new building fabric. Students had worked in close

\footnotetext{
8 Andrew Charleson, Mark Southcombe. "Strategies for the seismic upgrading of pairs of buildings in a historic precinct”, Bulletin of the New Zealand Society for Earthquake Engineering Vol. 50, n. I (March 20I7): 50-58.
} 
relation with their peers and demonstrated their engagement with context by showing adjacent work of their neighbours in their drawings. This structured mode of representation facilitated consideration of the effects of their work on the precinct and in relation to wider urban issues that had been identified in earlier group work. A composite $10 \mathrm{~m}$ long Cuba Street model was created incorporating every student project. The composite model communicated a collective vision that individual models could not, and it was very effective in communicating the vision for change in the precinct, and the range of its potential architectural approaches. The wider urban and architectural findings were disseminated through a number of invited public presentations in several New Zealand cities, in exhibitions, and through publications.

The design studios integrated teaching collaborations across parallel technology courses. As part of their architectural designs the students designed and integrated seismic retrofitting schemes to meet the requirements of the Building Act and the parallel integrated technologies courses. Structural, construction, and services knowledge was integral to seismic and architectural retrofit schemes for individual buildings and the clusters of buildings, including the intensification and new work. It is rare for clusters of buildings to be tied and seismically retrofitted together, so this phase of the project was important research into a new field.

A rich range of context-specific design investigations emerged. These interwove retrofitted structure with existing and new building fabric. Students worked in close relation to their peers prompted by a requirement to show peers' work as adjacent contexts in their drawings, and to consider the effect of their work on the wider precinct. They also created a composite $10 \mathrm{~m}$ long Cuba Street model incorporating each of their proposed projects. The composite model communicated a collective vision that individual models could not, and it was also very effective in communicating the potential for change in the precinct to a wider audience.

\section{Discussion}

The inputs to the project from the range of partners, consultants and stakeholders loosely occurred in the manner of a professional office-based project. Through the project students extended their depth of understanding of the architecture of the Cuba Street precinct in a direct manner analogous to the predesign phases of professional architectural practice, but also informed by their wider precinct urban investigations and analyses. They experienced the implications of their documentation accuracy in relation to a comparatively strict brief and their earlier design decision-making as they worked over, and then shared their earlier work. This achieved standards of documentation and student engagement in both project and process rarely seen within the university'. The level of engagement with representation and design limitations and opportunities was different to that of practice because of differences in the levels of site access, expertise and resources available in an equivalent practice context. This played out as a relative freedom and lack of student accountability to the professional consultants. There was also another factor at play; the structured accountability of students to their peers through the sharing of their project outputs with neighbouring students and the collective student group. Student project positioning relative to the wider student group and its specific theoretical context clearly had a major effect evident in the wide range of student approaches explored from conservative and pragmatic heritage conservation through to seriously radical reworking of heritage fabric and complete

\footnotetext{
${ }^{9}$ The formal feedback from professional tutors in the end of course incorporated in the report to management noted. "The design detail was resolved to a higher level of sophistication and resolution than expected, with some professional tutors noting this could be increased further".
}

162 | The Journal of Public Space, 2(3), 2017 | Special Issue | ISSN 2206-9658

(C) Queensland University of Technology 
demolition. The project facilitated a range of speculative design investigations and operated somewhere between professional and critical contexts, through addressing both the project detail and wider disciplinary framing.

The level of student engagement was also facilitated by the immediacy of the context. Many students in the cohort were directly affected by the Christchurch earthquakes, but all students were very familiar with downtown Cuba Street adjacent to the VUW schools of Architecture and Design campus. They readily appreciated the danger and immediacy of the problem, and that it affected the community seriously, including themselves. This context was very familiar to students, and the immediacy facilitated the testing of their ideas by direct comparison with the physical context they were designing for. Their engagement with owners and other affected parties and the publication of their work created the opportunity for their projects to be more than theoretical, and for their work to have a role helping address a key issue effecting the community.

The introduction of structural upgrading work required for the earthquake-prone heritage buildings into the design process was also a learning focus for the parallel technology course. The students discovered that seismic upgrading is interwoven with architectural implications and unable to be separated from them ${ }^{10}$. The extensive making-good and the remodelling associated with seismic retrofitting also triggered consideration of fire ratings, escape provisions, and accessibility enhancement. This created productive constraints that interacted with student design intentions, constraining and developing depth and quality of their design work in professional terms, and providing a context for critical development of the design and construction detail. The implications of technical requirements for design were addressed by students to an extent greater than usually possible thanks to the integration of the design and technologies courses and inputs from a large range of professional mentors and experts partially funded by the WCC.

There remained a difference in the significantly reduced level of detailed design that was able to be achieved within the academic context compared to what is possible in a professional context. This is as much an opportunity as a limitation. The student projects focused on individual design responses, but were also required to articulate a wider relationship to their disciplinary contexts; a wider architectural significance. In this case, the project dealt with questions regarding architectural opportunities associated with seismic upgrading and adaptive reuse of heritage building fabric. The deep connection to a real context with the ability to experiment free from the weight and insistence of a professional practice, created a wide range of alternative solutions to the one problem. The testing of a variety of solutions had a collective significance beyond the individual cases and this is the key difference to architectural outcomes in professional practice. Through a collective design-led research engine multiple engagement with the problem enabled the design, documentation and testing of a range of new strategies for seismic retrofitting clusters of buildings. It also enabled the design and modelling of a significant future vision for a whole part of the city. Subsequent publications relating to this studio project reflected on and theorised the range of architectural approaches possible to seismic retrofitting, and the synergies possible between clusters of buildings seismically retrofitted together ${ }^{\prime \prime}$, and the heritage implications of seismic

\footnotetext{
${ }^{10}$ Mark Southcombe and Andrew Charleson. [Re] Cuba: renegotiating seismic resilience in Cuba Street Wellington. Wellington City Council, 2014, 99.

" Mark Southcombe and Andrew Charleson. [Re] Cuba: renegotiating seismic resilience in Cuba Street Wellington. Wellington City Council, 2014, 14-17.
} 
retrofitting ${ }^{12}$. This wider dissemination of disciplinary critical reflection of design and research significance rarely occurs in practice where the discussion is skewed by the market ${ }^{13}$.

Through processes of working together, students also identified wider design opportunities for better urban design solutions. Collaborative aspects of the student project attempted to simulate an office environment through work in groups focused on a wider urban context of adjacent projects. This aspect of the academic project amplified student efforts through some shared predesign work and contextual information. They experienced added value to their projects through teamwork as noted by student Hamish Byrne... he and other students talked a lot about the relationships between their buildings, with the aim of making them work together aesthetically and functionally. He and Thomas, for example, collaborated on the redesign of a public space at the rear of the building, accessible from Glover Park ${ }^{14}$.

There was significant complementary production that added value to individual student work by sharing relevant research and documentation. This was particularly evident when the work of all 75 students in the cohort was combined in a series of combined street elevation drawings, and exhibition models of the entire future street designs.

These urban resources were valuable both to the student and wider public understanding of the shifts in existing urban patterns within the precinct. This was a distinctive outcome of the studio. Another example of the outcomes of this wide scope precinct research was the discovery of the importance of the underlying historical tiny scale site sizes to the somewhat grungy occupation of the precinct. This augmented the conventional understanding of the precinct character as arising not only from the poor condition of many of the buildings, but also from the unique range of small-scale tenancies. A diversity of vertical building scales was introduced as a tactic to help protect and at times recover and develop this Cuba Street specific urban character. Identifying these urban design characteristics and tactics to retain and augment key aspects of the genius loci was an unexpected and a valuable outcome for the WCC studio partner.

The amount of community engagement over the extent of the project was also noteworthy. Public meetings, public lectures, presentations, several public exhibitions and several academic publications occurred. The project took on a life of its own, attracting significant interest from the Cuba Street building owners and the wider New Zealand community. It achieved the objectives of raising public awareness of the seismic resilience issue and expanding the discourse around the range of potential solutions possible, particularly the potentials of major adaptive reuse and hybrid new-old building types.

A separate book project funded by WCC documented the collective analysis of the full length of the street and surrounds, individual and cluster case studies, and included an essay theorising an expanded range of architectural approaches to seismic retrofitting architecture $^{15}$. The $[R e] C u b a$ book is a major, publically accessible reference and resource demonstrating approaches to urban renewal and the seismic retrofitting of heritage buildings.

\footnotetext{
12 Jacqui Gibson, Future Perfect Heritage New Zealand, Autumn 20I3, 28-33.

13 Martin Pawley, "The Strange Death of Architectural Criticism", in The Strange Death of Architectural Criticism. Martin Pawley Collected Writings, Black Dog Publishing, 2007, 330-33I.

${ }^{14}$ Hamish Byrne, quoted by Jacqui Gibson, Future Perfect Heritage New Zealand, Autumn 20I3, 33

15 Mark Southcombe and Andrew Charleson, "Renegotiating the Architecture of Seismic Resilience", in [Re]

Cuba: Renegotiating Seismic Resilience in Cuba Street Wellington. Wellington City Council, 2014, 14- 17.
}

164 | The Journal of Public Space, 2(3), 20I7 | Special Issue | ISSN 2206-9658

(c) Queensland University of Technology 

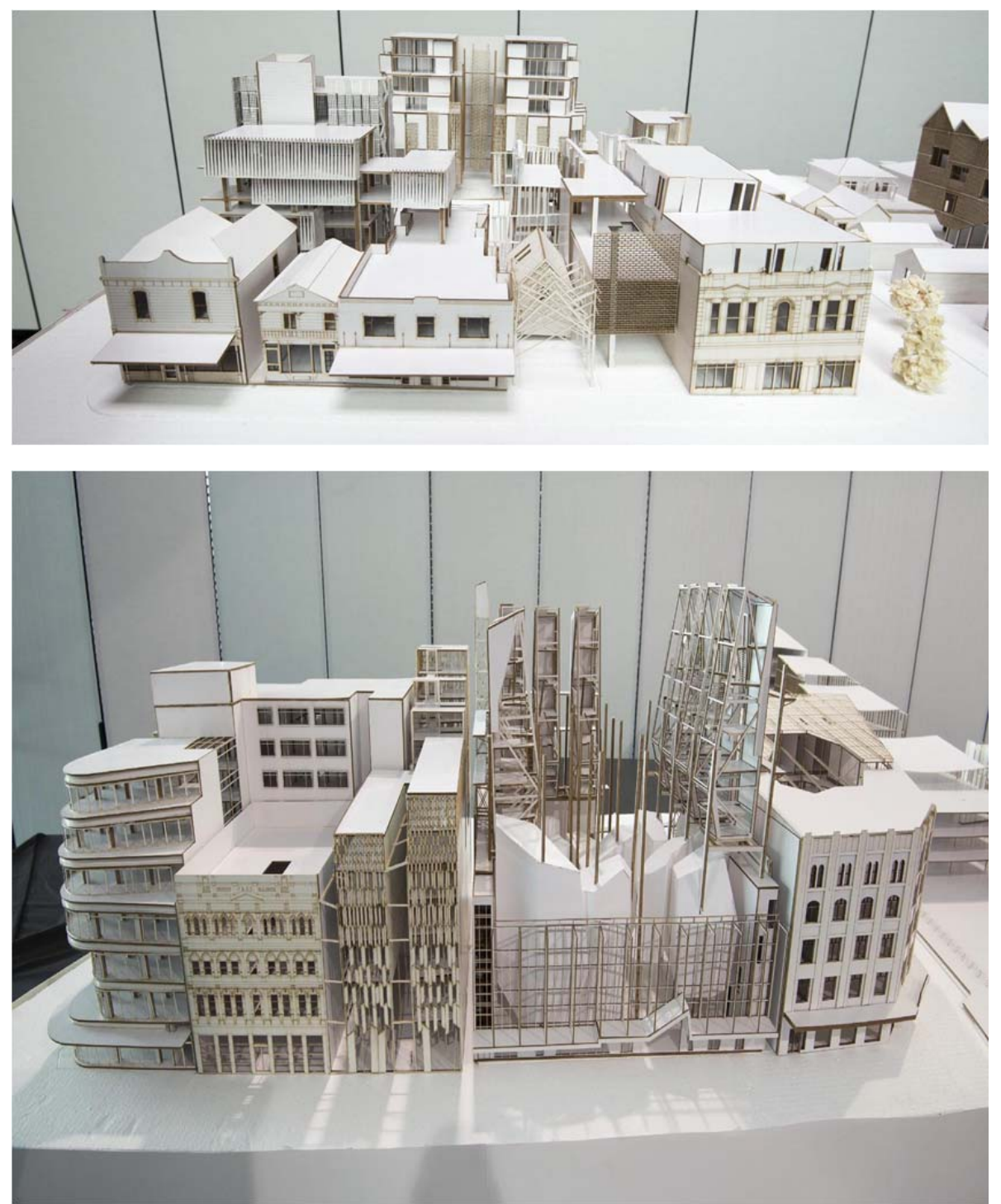

Figure 6 and Figure 7. [Re]Cuba Collective model Web Street end and Wakefield Street end 2013.

The large collective model exhibitions of research outcomes had significant impact upon the public, beyond that of smaller less engaged projects. They were exhibited in public venues in the city in response to external requests ${ }^{16}$. The project's wider reconsideration of the architectural implications of seismic retrofitting was public in nature, open, accessible, and promoted discourse. It created new knowledge and was documented though a variety of media. In contrast, professional practices even for public bodies occur through processes serving a particular client, their terms of reference, needs and preferences.

\section{Conclusion}

The collaboration between VUW, WCC, and HNZ, along with the inputs from professional Engineering and Architectural tutors, modelled a team approach to urban design and seismic retrofitting similar to a multidisciplinary office team. The knowledge exchange that occurred

\footnotetext{
${ }^{16}$ The New Zealand Society of Earthquake Engineers, the Wellington City Council, and Heritage New Zealand.
} 
through this process contributed significantly to the student engagement with the problem and the detail and quality of the student design results. It simulated a professional environment, informed design work, and shifted presentation in the direction of professional standards. Design work was also resolved with an increased level of detail sophistication and resolution over that achieved without professional mentorship. Students learnt from each other, and about how to work efficiently and effectively together. This was a significant pedagogical outcome in a teaching programme focused primarily on individual learning, and subject to the overview of a profession that operates through collaborative effort. Characteristics of professional and academic practices are significantly different even where academic practices attempt to simulate professional practices, and this affects the potential learning and sorts of outcomes that can be expected from them. Student abilities, the resources available and an academic context also play a role even when 'real world' briefs are simulated and extensive base information is provided and created as a part of a project, as occurred in the Cuba Street projects.

Understanding strengths, weaknesses and potentials of the different expectations and modes of operation in architectural education and professional practices is key to maximising the potential effectiveness of professional engagement were it occurs within architectural education. There are potential pedagogical, community and disciplinary impacts from a series of related and collective outputs to design investigations. These were experienced by the students who were directly implicated in the design context and maintained a high level of engagement throughout its progress. When a range of design-led research responses are coordinated as part of a single larger research project, the wider implications of the research can be demonstrated through comparison of related projects. These collective outcomes clearly have the potential to expand the level of engagement, not only of the students but also for the wider disciplinary and local communities. This occurs through the collective framing of the research, the breadth of the teasing out of an architectural question, the range of solutions generated, the collective manner of project representation, exhibition and publication, and the interaction with the host and wider communities through presentation, exhibition and publication.

The project outcomes covered an entire city precinct. The specific learning outcomes included awareness of efficiencies and architectural synergies from; seismic retrofits undertaken by architects with engineers, projects considering of clusters of neighbouring buildings, and from collaborative redevelopment introducing shared public laneways. The series of interactions before, during and after the period of the projects created a ripple of impacts through their associated seminars, exhibitions, lectures and publications. As a result, there is increased public awareness not only of the need to seismically retrofit local heritage buildings, but also of the value of architects' involvement in the problem, and the range potential architectural opportunities inherent to the problem, and their potential synergies. This type of broad urban, detailed, yet speculative investigation is rarely possible in practice where a project is limited by its client terms of reference and financial exigencies. The project created learning opportunities in association with studio partners' complementary objectives. Iterative implications of multiple alternative solutions were able to be explored in great breadth. The speculative freedom of the theoretical project also allowed the possibility to investigate the broad implications of the seismic retrofit architectural problem in a significantly wider manner than occurs in practice, and to draw new conclusions about the architectural implications of seismic retrofitting. 